\title{
DETERMINAÇÃO DO POTÁSSIO EM FERTILIZANTES POR FOTOMETRIA DE CHAMA DE EMIISSÃO *
}

\author{
J. C. ALCARDE ** \\ J. E. BORELLA ***
}

\section{RESUMO}

O presente trabalho teve por objetivo o estudo do método fotométrico de chama para a determinação do potássio em fertilizantes quando aplicado em extrato simplesmente aquoso e em extrato aquoso contendo oxalato de amônio, comparativamente com o método volumétrico do tetrafenilborato de sódio (TFBS).

Os dados obtidos mostraram que o método fotométrico de chama baseado no emprego de extratos simplesmente aquosos de fertilizantes apresentou resultados sempre inferiores ao obtidos pelo método do T.F.B.S. e seu relativo foi, em média, de $0,76 \%$ nos fertilizantes simples e em torno de - 3\% nas misturas de fertilizantes. O método fotométrico de chama baseado no emprego de extratos aquosos contendo oxalato de amônio apresentou resultados bastante próximos aos obtidos com o método do T.F.B.S. e seu erro relativo foi, em média, de - $0,35 \%$ nos fertilizantes simples e em torno de 0,7\% nas misturas de fertilizantes, mas com a alternância entre positivo e negativo. A preciasão foi elevada, mas esmerado cuidado é exigido nas diluições.

\section{INTRODUÇÃO}

Os métodos recomendados para a determinação do potássio em fertilizantes são: o método gravimétrico de Lindo-Gladding, baseado na precipitação do potássio como hexacloroplatinado de potássio, o método método volumétrico do tetrafenilborato de sódio e o método fotométrico de chama de emissão (OFFICIAL METHODS OF ANALYSIS OF A.O.A.C., 1975).

O método fotométrico de chama de emissão aplicado à determinação do potássio em fertilizantes foi apresentado pela primeira vez por SCHALL \& HAGELBERG (1952), os quais encontraram que sódio

\footnotetext{
* Entregue para a publicação em 30.12.76.

* Departamento de Química da ESALQ.

*** Bolsista do CNPq.
} 
e magnésio interferem positivamente quando suas concentrações são iguais ou superiores às de potássio, mas os cations cálcio e amônio e os anions cloreto, oxalato, nitrato e sulfato, na concentração de até $400 \mathrm{ppm}$, e ortofosfato monoácido na concentração de até 200 ppm não apresentaram nenhum efeito na emissão do potássio $(25 \mathrm{ppm})$; no entanto verificaram que o método fotométrico foi mais preciso e seus valores foram, no geral, ligeiramente menores e mais próximos do valor teórico de conteúdo de potássio nas amostras que os obtidos pelo método gravimétrico de Lindo-Gladding.

Considerando as possibilidades de interferência, Gehrke e colaboradores (1955-1957) introduziram o uso de resina de troca iônica para remover os ânions que interferem com a intensidade de emissão do potássio e o método foi adotado como oficial em 1960 pela Associação Oficial dos Químicos Agrícolas dos Estados Unidos (GEHRKE, USSARY \& KRAMER Jr., 1964). Posteriormente o método foi automatizado, ao mesmo tempo em que foi considerado desnecessário o uso da resina em amostras contendo até $16 \%$ de $\mathrm{K}_{2} \mathrm{O}$; amostras com teores mais elevados de $\mathrm{K}_{2} \mathrm{O}$ continuaram a exigir o uso da resina assim como mostraram baixa precisão em conseqüência das pequenas variações instrumentais, que eram aumentadas em função das grandes diluições necessárias (GEHRKE, USSARY \& KRAMER, 1964). Em seguida, após uma modificação no instrumento, a resina foi completamente eliminada (USSARY \& GEHRKE, 1965a. e 1965b). O método foi submetido a um estudo entre laboratórios (HAMBLETON, 1970 e 1971) e sugerida sua adoção oficial, passando a integrar a mais recente edição do OFFICIAL METHODS OF ANALYSIS OF THE A.O.A.C. (1975), mas mantendo ainda o método fotométrico de chama não automatizado e que faz uso da resina de troca iônica.

Em 1965, CATANI, GLORIA \& ROSSETO usando um fotômetro de chama Coleman, Modelo 21, estudaram o método fotométrico de chama para a determinação do potássio em fertilizantes e verificaram que os mais sérios interferentes foram fosfato e sulfato, mas não encontraram diferença quando determinaram o potássio em extratos aquosos de fertilizantes onde se procedeu a separação dos anions fosfato e sulfato em resina trocadora de ions e em extratos aquosos que não sofreram o citado tratamento. Esse método, no entanto, tem apresentado resultados que nem sempre correspondem aos obtidos com o método volumétrico do tetrafenilborato de sódio.

Confrontando os métodos fotométricos de chama apresentados por CATANI, GLORIA \& ROSSETO (1965) e por SCHALL e HAGELBERG (1952), a única diferença que merece consideração está no preparo do extrato aquoso contendo oxalato de amônio. Aliás, é interessante frisar que, durante toda a evolução do método fotomérico de chama para a determinação do potássio em fertilizantes, o extrato nunca foi simplesmente aquoso: inicialmente era obtido em presença de oxalato de amônio, que posteriormente foi substituído por carbonato de amônio e 
atualmente emprega-se novamente o oxalato de amônio, alterações estas não justificadas. Sabe-se que os anions oxalato e carbonato são precipitantes de cálcio e de magnésio assim como esses sais constituem um tampão de pH em torno da neutralidade, o que proporcionaria também a precipitação do ânion fosfato como fosfatos de cálcio ou de magnésio; nestas condições os principais interferentes seriam eliminados já no preparo do extrato.

Ainda quanto a metodologia para a determinação do potássio em fertilizantes devem ser citados os trabalhos de MCBRIDE (1967 e 1968), objetivando ampliar a aplicação da espectrofotometria de absorção atômica na determinação de nutrientes contidos nos fertilizantes; iniciou um estudo visando a determinação do potássio, sendo que os primeiros resultados não foram satisfatórios e empenho nesse sentido não tem sido observado.

No presente trabalho o objetivo foi estudar o método fotométrico de chama para a determinação do potássio em fertilizantes quando aplicado em extrato simplesmente aquoso e extrato aquoso contendo oxalato de amônio, comparativamente com o método volumétrico do tetrafenilborato de sódio que foi considerado como padrão.

\section{MATERIAL E MÉTODO}

\section{Material}

O material constou de fertilizantes potássicos simples comerciais, misturas de fertilizantes artificialmente preparadas em laboratório e misturas de fertilizantes comerciais.

As misturas artificiais, identificadas como A, B e C, foram preparadas a partir de produtos comerciais para conter apenas os nutrientes nitrogênio e fósforo e a composição das mesmas está descrita no QUADRO 1. O preparo dessas misturas foi feito colocando-se todos os componentes num gral de porcelana onde se procedeu a trituração e a homogeneização. Nessas misturas o potássio foi adicionado através de soluções padrões de $\mathrm{KC} 1$ au $\mathrm{K}_{2} \mathrm{SO}_{4}$ (contendo $10 \mathrm{mg}$ de $\mathrm{K}_{2} \mathrm{O} / \mathrm{ml}$ ), após a pesagem da amostra para a determinação; assim, a partir das misturas A, B e C foram obtidas outras com teores variáveis, mas exatamente conhecidos de $\mathrm{K}_{2} \mathrm{O}$, conforme mostra o QUADRO 2 .

Métodos

\section{Reativos}

Solução de oxalato de amônio a $4 \%$.

Solução padrão "estoque" de potássio. Dissolver 0,7456 g de KC1 p.a., seco a $105-110^{\circ} \mathrm{C}$ por uma hora, em água destilada, transferir 
QUADRO 1 - Composição das misturas de fertilizantes preparadas em laboratório

Componentes

$\%$ de cada componente na mistura

A $\quad$ B $\quad$ C

Salitre do Chile

40

Sulfato de amônio

$20 \quad 20$

Uréia

$20 \quad 10$

Fosfato diamônico

Superfosfato simples

30

10

Superfosfato triplo

Pirofilita vermelha

QUADRO 2 - Composição das misturas de fertilizantes com conteúdo exatamente conhecido de potássio

\begin{tabular}{cccc}
\hline Mistura $(\mathrm{N}-\mathrm{P})$ & $\begin{array}{c}\mathrm{ml} \text { da solução padrão } \\
\mathrm{K}_{2} \mathrm{SO}_{4}\end{array}$ & $\mathrm{KCl}$ & $\begin{array}{c}\text { Composição final } \\
\text { da mistura }\end{array}$ \\
\hline $\mathrm{A}$ & 10 & & $6-5-10$ \\
$\mathrm{P}$ & 5 & & $19-28-5$ \\
$\mathrm{P}$ & 10 & & $19-28-10$ \\
$\mathrm{~B}$ & 20 & 20 & $19-28-20$ \\
$\mathrm{~B}$ & 10 & & $19-28-20^{*}$ \\
$\mathrm{C}$ & & $10-24-10$ \\
\hline
\end{tabular}

* O asterisco identifica a prescnça de potássio na forma de cloreto.

para balão volumétrico de um litro e completar o volume. Esta solução é $0,010 \mathrm{~N}$ em $\mathrm{K}^{+}$.

Soluções padrões "de trabalho" de potássio. Transferir com micro-bureta, 1, 2, 3, 4 e $5 \mathrm{ml}$ da solução "estoque" de potássio para balões volumétricos de $100 \mathrm{ml}$ e completar o volume com água destilada. Estas soluções são, respectivamente, $0,0001 \mathrm{~N}, 0,0002 \mathrm{~N}, 0,0003 \mathrm{~N}, 0,0004 \mathrm{e}$ $0,0005 \mathrm{~N}$ em $\mathrm{K}^{+}$.

Soluções padrões "de trabalho" de potássio, em presença de diferentes quantidades de oxalato de amônio. Proceder como já descrito no preparo das soluções padrões de trabalho, mas acrescentando em cada série 0,$1 ; 0,2$ e $0,5 \mathrm{ml}$ de solução de oxalato de amônio a $4 \%$, antes de completar o volume. 
Soluções padrões de potássio contendo $10 \mathrm{mg}$ de $\mathrm{K}_{2} 0 / \mathrm{ml}$.

a - a partir de $\mathrm{K}_{2} \mathrm{SO}_{4}$ : dissolver $9,2494 \mathrm{~g}$ de $\mathrm{K}_{2} \mathrm{SO}_{4}$ p.a., seco a $105-110^{\circ} \mathrm{C}$ por uma hora, em água destilada, transferir para balão volumétrico de $500 \mathrm{ml}$ e completar o volume.

b - a partir de $\mathrm{KC} 1$ : dissolver $7,9143 \mathrm{~g}$ de $\mathrm{KC} 1 \mathrm{p}$.a., seco a $105-110{ }^{\circ} \mathrm{C}$ por uma hora, em água destilada, transferir para balão volumétrico de $500 \mathrm{ml}$ e completar o volume.

\section{Equipamento}

Fotômetro de chama Coleman, modelo 21, com filtro para potássio. A chama foi de butano e oxigênio com a pressão dos gases regulada em 2 e 10 psi, respectivamente.

Método fotométrico de chama de emissão

\section{1 - Preparo do extrato}

1.1 - Em solução aquosa (CATANI, GLORIA e ROSSETO, 1965). Dissolver $1,0000 \mathrm{~g}$ da amostra em água destilada, filtrar por papel $\mathrm{S} \& \mathrm{~S}$ 589, faixa branca ou equivalente para balão volumétrico de $500 \mathrm{ml}$, lavar bem o recipiente em que foi feita a dissolução e o filtro com água destilada e completar o volume.

1.2 - Em solução aquosa contendo oxalato de amônio (OFFICIAL METRODS OF ANALYSIS OF THE A.O.A.C., 1975). Pesar 1,0000 g da amostra, transferir para copo de $400 \mathrm{ml}$, acrescentar $125 \mathrm{ml}$ de água destilada e $50 \mathrm{ml}$ de solução de oxalato de amônio a 4\%. Cobrir com vidro de relógio, ferver lentamente por trinta minutos, esfriar e filtrar por papel S \& S 589, faixa branca ou equivalente, recebendo o filtrado num balão volumétrico de $500 \mathrm{ml}$. Lavar muito bem o copo em que foi feita a precipitação, e o filtro e completar o volume.

\section{2 - Determinação}

a - Transferir $10 \mathrm{ml}$ do extrato de fertilizante para balão volumétrico de $500 \mathrm{ml}$ (se fertilizante simples) ou de $250 \mathrm{ml}$ (se mistura) e completar o volume com água destilada.

b - Proceder a leitura dessa solução no fotômetro de chama, acertando o zero com água destilada e o $100 \mathrm{com}$ a solução $0,0005 \mathrm{~N} \mathrm{em} \mathrm{K} \mathrm{K}^{+}$.

c - A concentração de $\mathrm{K}^{+}$ou $\mathrm{K}_{2} \mathrm{O}$ na solução final, em e.mg $/ \mathrm{ml}$, é dada pela expressão: 
sendo,

$$
\mathrm{x}=5 \times \mathrm{L} \times 10^{-6}
$$

$$
\begin{aligned}
& \mathrm{x}=\text { concentração de } \mathrm{K}^{+} \text {ou } \mathrm{K}_{2} \mathrm{O} \text { na solução final, em e.mg } / \mathrm{ml} \\
& \mathrm{L}=\text { leitura }
\end{aligned}
$$

Método volumétrico do tetrafenilborato de sódio (TFBS)

O método empregado foi o descrito no OFFICIAL METHODS OF ANALYSIS OF THE A.O.A.C. (1975).

\section{RESULTADOS OBTIDOS E DISCUSSÃO}

\section{Linearidade da curva padrão em função da concentração de potássio}

Esse estudo teve por objetivo aumentar a concentração das soluções padrões de potássio visando reduzir o número de diluições a que deve ser submetida a solução da amostra de fertilizante para a determinação do potássio pelo método fotométrico de chama. A partir da solução padrão "estoque" de potássio e a semelhança das soluções padrões "de trabalho" diversas séries de soluções padrões "de trabalho" de concentrações diferentes foram preparadas e efetuadas as respectivas leituras no fotômetro, acertando o zero sempre com água destilada e o $100 \mathrm{com}$ a solução mais concentrada da respectiva série. Os resultados acham-se descritos no Quadro 3 e representados graficamente na Figura 1. Observa-se que a linearidade só é apresentada pela primeira (1.a) série de padrões, onde a variação da concentração de potássio foi de 0 a $0,0005 \mathrm{~N}$, isto é, de 0 a 19,55 ppm deK+ ou de 0 a 23,55 ppm de $\mathrm{K}_{2} \mathrm{O}$.

\section{Influência da presença de oxalato de amônio}

GEHRKE, USSARY \& KRAMER (1964) encontraram que o anion oxalato apresenta uma pequena interferência positiva quando em concentraçáo acima de 20 ppm. CATANI, GLORIA \& ROSSETO (1965) verificaram que o ion amônio não interfere, pelo menos até a concentração estudada de 1.000 ppm. Nas condições da presente determinação a concentração do anion oxalato na solução final a ser lida é de 57 ou $114 \mathrm{ppm}$, aproximadamente. Isso exigiu um estudo da influência desse anion, o que foi feito preparando soluções padrões de potássio contendo $0 ; 0,1 ; 0,2 ;$ e $0,5 \mathrm{ml}$ da solução de oxalato de amônio a $4 \%$ em $100 \mathrm{ml}$, que corresponde a $0 ; 28,4 ; 56,8$; e 142 ppm do anion oxalato respectivamente. Os resultados estão descritos no Quadro 4.

Conforme pode ser notado a presença do anion oxalato não interferiu na leitura das soluções padrões de potássio, pelo menos quando presente numa concentração de até 142 ppm. 


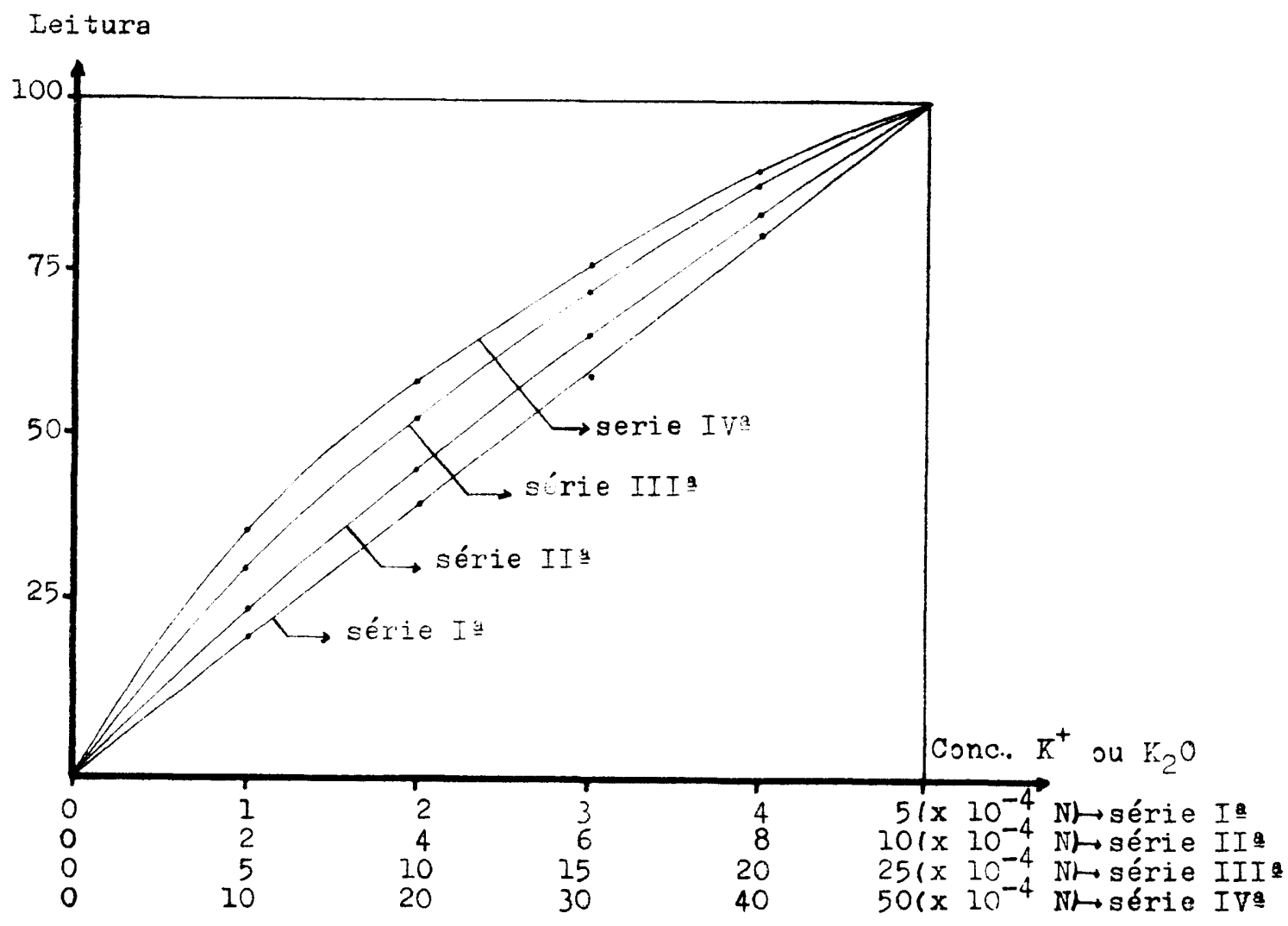

QUADRO 3 - Curvas padrões de potássio obtidas com diversas séries de soluções padrões de potássio de diferentes concentrações

\begin{tabular}{|c|c|c|c|c|c|c|c|c|}
\hline Série & & $\begin{array}{l}\text { Concentração de } \\
\mathrm{K}^{+} \text {nas soluçôes } \\
\text { padrões }\end{array}$ & Leituras & & Série & & $\begin{array}{c}\text { Concentração de } \\
\mathrm{K}^{+} \text {nas soluções } \\
\text { padrões }\end{array}$ & Leituras \\
\hline \multirow[t]{6}{*}{ I.a } & & 0 (água) & 0 & \multirow[t]{6}{*}{ II.a } & 1 & & 0 (água) & 0 \\
\hline & & $0,0001 \mathrm{~N}$ & 20 & & 2 & & $0,0002 \mathrm{~N}$ & 24 \\
\hline & & $0,0002 \mathrm{~N}$ & 40 & & 3 & & $0,0004 \mathrm{~N}$ & 45 \\
\hline & & $0,0003 \mathrm{~N}$ & 59 & & 4 & & $0,0006 \mathrm{~N}$ & 65 \\
\hline & & $0,0004 \mathrm{~N}$ & 80 & & 5 & & $0,0008 \mathrm{~N}$ & 83 \\
\hline & & $0,0005 \mathrm{~N}$ & 100 & & 6 & & $0,0010 \mathrm{~N}$ & 100 \\
\hline \multirow[t]{6}{*}{ III.a } & 1 & 0 (água) & 0 & \multirow{6}{*}{\multicolumn{2}{|c|}{ IV.a }} & 1 & 0 (água) & 0 \\
\hline & 2 & $0,0005 \mathrm{~N}$ & 30 & & & 2 & $0,0010 \mathrm{~N}$ & 36 \\
\hline & 3 & $0,0010 \mathrm{~N}$ & 53 & & & 3 & $0,0020 \mathrm{~N}$ & 58 \\
\hline & 4 & $0,0015 \mathrm{~N}$ & 71 & & & 4 & $0,0030 \mathrm{~N}$ & 75 \\
\hline & 5 & $0,0020 \mathrm{~N}$ & 87 & & & 5 & $0,0040 \mathrm{~N}$ & 89 \\
\hline & 6 & $0,0025 \mathrm{~N}$ & 100 & & & 6 & $0,0050 \mathrm{~N}$ & 100 \\
\hline
\end{tabular}


QUADRO 4 - Efeito da presença de oxalato de amônio na leitura das soluções padiões de potássio

\begin{tabular}{cccccccc}
\hline \multirow{2}{*}{$\begin{array}{c}\text { ppm de } \mathrm{C}_{2} \mathrm{O}_{4}{ }^{2-} \\
\text { nas soluçôes }\end{array}$} & 0 & $0,0001 \mathrm{~N}$ & $0,0002 \mathrm{~N}$ & $0,0003 \mathrm{~N}$ & $0,0004 \mathrm{~N}$ & $0,0005 \mathrm{~N}$ \\
\cline { 2 - 5 } & 0 & 20,0 & 39,0 & 60,0 & 79,0 & 100 \\
\hline 0,0 & 0 & 20,0 & 39,0 & 59,5 & 80,5 & 100 \\
28,4 & 0 & 19,5 & 40,5 & 59,5 & 79,5 & 100 \\
56,8 & 0 & 20,0 & 40,0 & 60,0 & 80,0 & 100 \\
142,0 & & & & & & \\
\hline
\end{tabular}

\section{Determinação do potássio em fertilizantes simples}

Os fertilizantes potássicos simples, que comumente são o sulfato de potássio e o cloreto de potássio, apresentam elevado teor de $\mathrm{K}, \mathrm{O}$, o que exige uma grande diluição no extrato para a determinação fotométrica de chama. Em amostras comerciais daqueles produtos determinou-se o potássio pelo método volumétrico do TFBS e pelo método fotométrico de chama usando extrato aquoso e extrato em presença de oxalato de amônio. Os resultados estão relatados no Quadro 5.

QUADRO 5 - Resultados da determinação do potássio em fertilizantes simples pelos métodos: (I) volumétrico do TFBS, (II) fotométrico de chama usando extrato aquoso, e (III) fotométrico de chama usando extrato aquoso em presença de oxalato de amônio (média de 3 repetições)

\begin{tabular}{lccccc}
\hline \multirow{2}{*}{ Fertilizantes } & \multicolumn{5}{c}{$\%$ de $\mathrm{K}_{2} \mathrm{O}$ determinada } \\
\cline { 2 - 6 } & Método (1) & Método (II) & $\mathrm{E}_{\mathrm{r}} \%^{ \pm}$ & Método (III) & $\mathrm{E}_{\mathrm{r}} \%$ * \\
\hline \hline Cloreto de potássio & $60,26 \pm 0,000$ & $59,93 \pm 0,000$ & $-0,55$ & $59,93 \pm 0,000$ & -0.55 \\
Sulfato de potáássio & $48,05 \pm 0,000$ & $47,59 \pm 0,000$ & $-0,96$ & $47,98 \pm 0,029$ & -0.15 \\
\hline
\end{tabular}

* Erro relativo porcentual, em relação ao método (I)

Os dados mostram que para o cloreto de potássio as duas diferentes técnicas de preparo do extrato de fertilizante para a determinação fotométrica não diferiram entre si, apresentando em ambos os casos um erro relativo de $-0,55 \%$ em relação ao resultado obtido pelo método do TFBS. Já no caso do sulfato de potássio as diferentes técnicas de preparo do extrato proporcionaram resultados diferentes, sendo o resul- 
tado do método fotométrico baseado no uso de extrato aquoso (método II) inferior ao obtido com o método fotométrico baseado no uso de extrato aquoso em presença de amônio (método III); o erro relativo do método II foi de $-0,96 \%$ e do método III de $-0,15 \%$ em relação ao resultado obtido com o método do TFBS. Para os fertilizantes simples estudados o erro relativo médio do método II foi de $-0,76 \%$ e o do método III foi de $-0,35 \%$.

Determinação do potássio em misturas de fertilizantes preparadas em laboratório com teores conhecidos de potássio

Os resultados da determinação do potássio nas misturas de fertilizantes artificialmente preparadas em laboratórios e contendo um teor exatamente conhecido de $\mathrm{K}_{2} \mathrm{O}$, usando os métodos em estudo no presente trabalho se encontram no Quadro 6.

QUADRO 6 - Resultados da determinação do potássio em misturas de fertilizantes, artificialmente preparados e contendo $\mathrm{um}$ teor conhecido de $\mathrm{K}_{2} \mathrm{O}$, pelos métodos: (I) volumétrico do TFBS; (II) fotométrico de chama, usando extrato aquoso e (III) fotométrico de chama usando extrato aquoso em presença de oxalato de amônio (média de três repetições)

\begin{tabular}{lrrrrr}
\hline \multirow{2}{*}{ Misturas } & \multicolumn{5}{c}{$\%$ de $\mathrm{K}_{2} \mathrm{O}$ determinada } \\
\cline { 2 - 7 } & Método (I) & Método (II) & $\mathrm{E}_{\mathrm{r}} \% *$ & Método (III) & $\mathrm{E}_{\mathrm{r}} \% *$ \\
\hline \hline $\mathrm{A}(06-05-10)$ & $10,03 \pm 0,000$ & $9,79 \pm 0,168$ & $-2.39 \%$ & $10,38 \pm 0,000$ & $-3,49 \%$ \\
$\mathrm{~B}(19-28-05)$ & $5,01 \pm 0,000$ & $4,80 \pm 0,169$ & $-4,19 \%$ & $4,99 \pm 0,000$ & $-0,40 \%$ \\
$\mathrm{~B}(19-28-10)$ & $10,03 \pm 0,000$ & $9,79 \pm 0,170$ & $-2,39 \%$ & $9,99 \pm 0,000$ & $-0,40 \%$ \\
$\mathrm{~B}(19-28-20)$ & $20,07 \pm 0,664$ & $19,29 \pm 0,170$ & $-3,89$ & $19,98 \pm 0,000$ & $-0,45 \%$ \\
$\mathrm{~B}(19-28-20)^{ \pm}$ & $20,07 \pm 0,664$ & $19,29 \pm 0,170$ & $-3,89$ & $19,98 \pm 0,000$ & $-0,45 \%$ \\
$\mathrm{C}(10-24-10)$ & $10,03 \pm 0,000$ & $9,79 \pm 0,170$ & $-2,39$ & $10,04 \pm 0,268$ & $+0,10 \%$ \\
\hline
\end{tabular}

* Erro relativo porcentual, em relação ao método (1)

Os dados mostram que o método fotométrico de chama que usa extrato aquoso (método II) apresentou todos os resultados inferiores aos obtidos pelo método volumétrico do TFBS, cujos erros relativos apresentaram uma média de $-3,19 \%$. Por outro lado o método fotométrico que usa extrato aquoso em presença de oxalato de amônio apresentou resultados muito mais próximos aos obtidos pelo método do TFBS e consequentemente erros relativos menores e cuja média foi de 
$0,88 \%$, assim como os erros alternaram-se entre positivos e negativos. Deve ser observada a excelente concordância entre os resultados obtidos pelo método volumétrico do TFBS e os teores conhecidos de $\mathrm{K}_{2} \mathrm{O}$ presentes nas misturas.

\section{Determinação do potássio em misturas de fertilizantes comerciais}

Finalmente, diversas misturas de fertilizantes comerciais foram analisadas pelos métodos em estudo e os resultados estão mostrados no QUADRO 7.

QUADRO 7 - Resultados da determinação do potássio em misturas comerciais de fertilizantes, pelos métodos: (I) volumétrico do TFBS; (II) fotométrico de chama usando extrato aquoso e (III) fotométrico de chama usando extrato aquoso em presença de oxalato de amônio (média de três repetições).

\begin{tabular}{lrrrrrr}
\hline \multirow{2}{*}{ Misturas } & \multicolumn{5}{c}{$\%$ de $\mathrm{K}_{2} \mathrm{O}$ determinada } \\
\cline { 2 - 6 } \cline { 5 - 7 } & Método (I) & Método (II) & $\mathrm{E}_{\mathrm{r}} \%^{*}$ & Método (III) & $\mathrm{E}_{\mathrm{r}} \% *$ \\
\hline \hline $05-35-05$ & $8,65 \pm 0,106$ & & $8,14 \pm 0,080$ & $-5,90$ & $8,58 \pm 0,128$ & $-0,81$ \\
$00-22-09$ & $8,01 \pm 0,047$ & $7,78 \pm 0,000$ & $-2,87$ & $8,11 \pm 0,066$ & $+1,25$ \\
$10-10-10$ & $8,56 \pm 0,049$ & $8,37 \pm 0,000$ & $-2,22$ & $8,52 \pm 0,000$ & $-0,47$ \\
$13-13-15$ & $15,10 \pm 0,186$ & $14,72 \pm 0,065$ & $-2,52$ & $14,92 \pm 0,131$ & $-1,19$ \\
$04-33-10$ & $10,59 \pm 0,049$ & $10,28 \pm 0,000$ & $-2,93$ & $10,58 \pm 0,000$ & $-0,09$ \\
$20-06-20$ & $20,92 \pm 0,039$ & $20,65 \pm 0,080$ & $-1,29$ & $21,00 \pm 0,000$ & $+0,38$ \\
$13-13-25$ & $25,24 \pm 0,151$ & $24,59 \pm 0,080$ & $-2,58$ & $25,00 \pm 0,066$ & $-0,95$ \\
\hline
\end{tabular}

* Erro relativo porcentual, em relação ao método (I).

Os resultados confirmaram as diferenças já obtidas em função da técnica de preparo do extrato para a determinação fotométrica, isto é, o método baseado no uso de extratos aquosos apresentou resultados inferiores aos obtidos pelo método baseado no uso de extratos aquosos contendo oxalato de amônio. Cmparando os resultados desses dois métodos com os do método volumétrico do TFBS, o método fotométrico que emprega extratos aquosos apresentou erros relativos cuja média foi de 2,90 e sempre negativos, enquanto os erros relativos do método fotométrico empregando extratos aquosos contendo oxalato de amônio tiveram uma média de $0,73 \%$ e com alternância entre positivos e negativos. 


\section{CONCLUSÕES}

Os resultados obtidos no presente trabalho permitem as seguintes conclusões:

1 - A linearidade da curva padrão foi obedecida dentro do intervalo de concentração de potássio de 0 a $0,0005 \mathrm{~N}$, isto é, de 0 a $19,55 \mathrm{ppm}$ de $\mathrm{K}^{+}$ou de 0 a $23,55 \mathrm{ppm}$ de $\mathrm{K}_{2} \mathrm{O}$.

2 - O método fotométrico de chama baseado no emprego de extratos simplesmente aquosos de fertilizante apresentou sempre resultados inferiores aos obtidos com o método volumétrico do tetrafenilborato de sódio. $\mathrm{O}$ erro relativo desse método fotométrico foi, em média, de $0,76 \%$ nos fertilizantes simples e em torno de $3 \%$ nas misturas de fertilizantes, sempre negativos.

3 - O método fotométrico de chama baseado no emprego de extratos aquosos contendo oxalato de amônio apresentou resultados bastante próximos dos obtidos com o método volumétrico do tetrafenilborato de sódio. O erro relativo desse método fotométrico foi, em média, de $-0,35 \%$ nos fertilizantes simples e em torno de $0,7 \%$ nas misturas de fertilizantes mas com alternâncias entre positivo e negativo.

4 - A precisão dos métodos estudados foi elevada, mas principalmente os métodos fotométricos exige esmerado cuidado nas diluições.

SUMMARY

DETERMINATION OF POTASSIUM IN FERTILIZERS BY EMISSION FLAME PHOTOMETRY

In this paper was studied the flame photometric method for potassium determination in fertilizers using only aqueous extract of fertilizer and aqueous extract content ammonium oxalate, comparatively with the volumetric sodium tetraphenyboron (STPB) method.

The flame photometric method using only aqueous extract presented results always lown of that STPB method being its relative error on an avarage $-0.76 \%$ with potassium fertilizer materials and approximately $-3 \%$ with mixtures. The flame photometric method using aqueous extract content ammonium oxalate presented results enough near that STPB method, being its relative error on an avarage $-0.35 \%$ with potassium fertilizer materials and approximately $0.7 \%$ with mixtures but alternated among positive and negative error. The precision of both photometric method is very high but it must have much care with dilutions, that are larges. 


\section{LITERATURA CITADA}

CATANI, R.A.; N.A. DA GLORIA \& A.J. ROSSETO, 1965. Determinação do potássio em fertilizantes por fotometria de chama. Anais da E.E.A. "Luiz de Queiroz", $22: 12-25$.

GEHRKE, C.W.; J.P. USSARY \& G.H. KRAMER Jr.( 1964. Automation of the AOAC Flame Photometric Method for Potassium in Fertilizers. J. of Ass. Off. Agric. Chem., 47 (3) : 459-469.

HAMBLETON, L.G., 1970. Collaborative study on an automated method for $\mathrm{K}_{2} \mathrm{O}$ in fertilizers. J. of Ass. Off. Anal. Chem. 53(3):456-460.

HAMBLETON, L.G., 1971. Collaborative study of the automated method for $\mathrm{K}_{2}$ in fertilizers. J. of Ass. Off. Anal. Chem. 54(3):646-650.

MCBRIDE, C.H., 1967. Determination of secundary and minor plant nutrients in fertilizers by atomic absorption spectrophotometry: third collaborative study. J. of. Ass. Ofi. Agr. Chem., 50(2) : 401-407.

MCBRIDE, C.H.; 1968. Determination of secundary and minor plant nutrients in fertilizers by atomic absorption spectrophotometry: IV. J. of Ass. Off. Agric. Chem., 54(1): 847-851.

OFFICIAL METHODS OF ANALYSIS OF THE A.O.A.C., 1975. 12 $2^{\text {th }}$ edition. p. 19-22. Published by the Association of Official Analytical Chemists, Washington, D.C.

SCHALL, E.D. \& R.R. HAGELBERG, 1952. Application of flame photometry to the determination of potash in fertilizers. J. of Ass. Off. Agric. Chem., 35(3):757-764.

USSARY, J.P. \& C.W. GEHRKE, 1965.a. Automation of the flame photometric method for potassium in fertilizer grade potassium salts. J. of. Ass. Off. Agric. Chem., $48(4): 865-868$.

USSARY, J.P. \& C.W. GEHRKE, 1965.b. Automatic flame photometric determination of potassium in fertilizers. A. Elimination of anion exchange cleanup. B. Using direct available $\mathrm{P}_{2} \mathrm{O}_{5}$ extract. J. of Ass. Off. Agric. Chem., 48(6) : 1095-1103. 